\title{
Variability of red rot-resistant somaclones of sugarcane genotype S97US297 assessed by RAPD and SSR
}

\author{
M.T.H. Shahid ${ }^{1}$, F.A. Khan' ${ }^{2}$ A. Saeed ${ }^{2}$ and I. Fareed ${ }^{2}$ \\ ${ }^{1}$ Ayub Agricultural Research Institute, Faisalabad, Pakistan \\ ${ }^{2}$ Department of Plant Breeding and Genetics, University of Agriculture, \\ Faisalabad, Pakistan \\ Corresponding author: F.A. Khan \\ E-mail: farooq pbg@yahoo.com
}

Genet. Mol. Res. 10 (3): 1831-1849 (2011)

Received October 25, 2010

Accepted March 25, 2011

Published August 26, 2011

DOI http://dx.doi.org/10.4238/vol10-3gmr1122

\begin{abstract}
Sugarcane breeding under climatic conditions of Pakistan is very difficult due to unavailability of viable fuzz (seed). Somaclonal variation can provide an alternative for improvement of existing genotypes. Six hundred and twenty-seven somaclones were developed from sugarcane genotype S97US297, and protocols for callogenesis and organogenesis were developed using Murashige and Skoog medium. Two types of explants, leaf and pith, and two auxins, 2,4-dichlorophenoxy acetic acid and indole-3-acetic acid, were tested to optimize callogenesis for root establishment. Leaves as explants with $3.0 \mathrm{mg} / \mathrm{L} 2,4$-dichlorophenoxy acetic acid gave the best results, both for callus induction and proliferation. Half-strength Murashige and Skoog medium with $1.5 \mathrm{mg} / \mathrm{L}$ indole-3-butyric acid proved to be the best for rooting. Red rot-resistant somaclones of the $\mathrm{R}_{2}$ generation along with the parent were assessed for genetic variability at the molecular level using RAPD and SSR markers. Polymorphism based
\end{abstract}


on RAPD and SSR was 32 and $67 \%$, respectively. Polymorphic information content ranged from $0.06-0.45$ for RAPD and 0.06-0.47 for SSR. We conclude that somaclonal variation of sugarcane varieties is sufficient to allow selection.

Key words: Sugarcane; SSR; RAPD; Red rot; Variability

\section{INTRODUCTION}

Globally, sugarcane (Saccharum spp) is an important source of commercial sugar accounting for almost two-thirds of world sugar production (Menossi et al., 2008). Pakistan ranks 5 th in world production. It is the second largest cash crop of Pakistan, with a production of 50.05 million tonnes in the year 2008-2009 (Anonymous, 2008). This indicates the importance of continuous breeding efforts for the production of high-yielding and diseaseresistant cultivars. Red rot disease caused by the fungus Colletotrichum falcatum Went. is one of the major constraints for sugarcane production in Pakistan. This disease caused the greatest loss to the sugarcane industry in Pakistan during the period of 2003-2006. About $29.07 \%$ loss in cane weight was recorded, which resulted in $30.8 \%$ loss in sugar recovery (Hussnain and Afghan, 2006).

In sugarcane breeding, flowering induction or tasselling is of paramount importance. Unfortunately, climatic conditions are not favorable for flowering in Pakistan. Thus, the variety development program depends mainly on the import of fuzz from the USA, Brazil, Barbados, South Africa, Mauritius, and Australia (Malik, 1990). This emphasizes the need to explore new horizons to augment the existing varietal development program.

Somaclonal variation has emerged as an important parasexual tool for crop improvement. This technique has been developed as a breeding tool for improving the quality and production of vegetatively propagated crops such as sugarcane (Siddiqui et al., 1994). Somaclones show variation for different parameters such as yield, sugar recovery, disease resistance, drought tolerance, and maturity. Assessment of genetic variability in tissue culture-derived plants would be helpful for plant breeders to select appropriate material for their breeding program.

Technological advances in molecular biology have contributed greatly to understanding the genetic diversity of plants. Molecular markers are used to measure the extent of variation at the genetic level, within and among populations. Random amplified polymorphic DNA (RAPD) and simple sequence repeat (SSR) markers are the most commonly used molecular techniques to study polymorphism in sugarcane (Oropeza et al., 1995; Nair et al., 1999, 2002). SSRs are highly polymorphic compared to other marker techniques such as RFLPs and RAPDs (Powell et al., 1996), and they can detect polymorphism even between closely related lines and require less quantity of DNA.

The genotype S97US297 used in this study was received from the Sugarcane Research Institute, Faisalabad, Pakistan. This is a good yielder with more than $11 \%$ sugar recovery, but is susceptible to red rot. The development of somaclones requires optimum conditions for callus induction and regeneration of plantlets from an explant source. The aim of the present study was to identify the best explant source and optimize medium for callogenesis and organogenesis for the sugarcane genotype S97US297. The other objective 
of this study was to assess the genetic variability among the selected red rot-resistant somaclones and their parent by RAPD and SSR markers. This information will enrich the ongoing breeding program by somaclonal variation and will help to overcome the breeding problems caused by unfavorable climatic conditions in Pakistan.

\section{MATERIAL AND METHODS}

\section{Plant tissue culture (development of sugarcane somaclones)}

Leaf and pith explants were used to develop calli. The innermost young leaves above the apical meristem and the pith below the meristem, both $0.5 \mathrm{~mm}$ in size were excised under aseptic conditions and cultured on Murashige and Skoog (1962) (MS) medium supplemented with 2,4-D (2,4 dichlorophenoxy acetic acid) and IAA (indole acetic acid) at 1, 3, 5, 7, and $9.0 \mathrm{mg} / \mathrm{L}$ for callogenesis. For organogenesis, calli developed with each auxin were cultured separately on MS medium containing kinetin at $0.1,0.5,1.0,1.5$, and $2.0 \mathrm{mg} / \mathrm{L}$ along with 480 $\mathrm{mg} / \mathrm{L}$ casein hydrolysate as nutritional supplement. Differentiated shoots were separated and shifted to the rooting medium with 50 and $100 \%$ concentration of MS salts supplemented with five different concentrations, i.e., 0.1, 0.5, 1.0, 1.5, and $2.0 \mathrm{mg} / \mathrm{L}$ IBA (indole-3-butyric acid) or NAA (1-naphthaleneacetic acid).

Sucrose in the medium was added at $3.0 \%$. The $\mathrm{pH}$ of the medium was adjusted to 5.7 \pm 0.1 with $0.1 \mathrm{~N} \mathrm{HCl}$ or $5 \% \mathrm{NaOH}$. Phyta-Jell ${ }^{\mathrm{TM}}$, at $1.5 \mathrm{~g} / \mathrm{L}$ was used to solidify the medium. Ten milliliters molten medium was dispensed in each test tube, and 30 test tubes were used for each treatment. Autoclaving was performed for $20 \mathrm{~min}$ at $121^{\circ} \mathrm{C}$ and $1.2 \mathrm{~kg} / \mathrm{cm}^{2}$ pressure.

Callus cultures were kept in the dark for the first 15 days at $28 \pm 1^{\circ} \mathrm{C}$ and then shifted to light at 2000 to 3000 lux for $16 \mathrm{~h}$. The same temperature and light intensity was used for organogenesis and root formation.

Data for callus induction and degree of callus formation were recorded, first at the completion of the dark period and then weekly afterward as follows: (0) for no callus; (1) for poor callus; (2) for fair callus; (3) for good callus, and (4) for excellent callus. Data regarding regeneration percentage and number of shoots obtained for each treatment were recorded after 40 days, whereas data regarding root initiation and number of roots developed by each plantlet were recorded after 30 days.

In vitro regenerated plantlets were taken out from test tubes and washed under running tap water until the callus residue was removed. Plantlets were then shifted to greenhouse conditions for hardening until the sowing season. Statistical analysis, determining and assessing means, standard errors and mean squares, was performed using standard methods.

\section{Molecular studies}

Field testing was carried out to assess the resistance of somaclones against red rot disease by inoculating with the respective pathotype by the bore hole method under field conditions. A total of 15 somaclones that showed resistance against red rot for three consecutive generations, i.e., $\mathrm{R}_{0}, \mathrm{R}_{1}$ and $\mathrm{R}_{2}$, were used in the molecular study (Table 1 ). Two types of DNA markers, RAPD and SSR, were utilized to determine the genetic variability among somaclones and their parent. 


Table 1. List of somaclones along with their donor parents used.
\begin{tabular}{lllcll}
\hline Sr. No. & Somaclone & Donor & Sr. No. & Somaclone & Donor \\
\hline 1 & S97US297-01 & S97-US-297 & 9 & S97US297-09 & S97-US-297 \\
2 & S97US297-02 & S97-US-297 & 10 & S97US297-10 & S $97-U S-297$ \\
3 & S97US297-03 & S97-US-297 & 11 & S97US297-11 & S97-US-297 \\
4 & S97US297-04 & S97-US-297 & 12 & S97US297-12 & S97-US-297 \\
5 & S97US297-05 & S97-US-297 & 13 & S97US297-13 & S $97-U S-297$ \\
6 & S97US297-06 & S97-US-297 & 14 & S97US297-14 & S97-US-297 \\
7 & S97US297-07 & S97-US-297 & 15 & S97US297-15 & S97-US-297 \\
8 & S97US297-08 & S97-US-297 & 16 & S97-US-297 & Donor \\
\hline
\end{tabular}

DNA was extracted from young leaves by adopting the CTAB method (Doyle and Doyle, 1990). DNA concentration was determined using a NanoDrop Spectrophotometer (ND 1000). In total, 150 RAPD and SSR primers were used in the study. Of 100 RAPD primers (GeneLink, USA) only 20 were polymorphic (Table 2). Of the 50 SSR primers (GeneLink, USA) studied, 28 showed polymorphism (Table 3 ).

Table 2. List of polymorphic RAPD primers.

\begin{tabular}{|c|c|c|c|c|c|}
\hline Sr. No. & Oligo name & Sequence $\left(5^{\prime}-3^{\prime}\right)$ & Sr. No. & Oligo name & Sequence (5'-3') \\
\hline 1 & GL DecamerA-02 & TGCCGAGCTG & 11 & GL DecamerA-20 & GTTGCGATCC \\
\hline 2 & GL DecamerA-03 & AGTCAGCCAC & 12 & GL DecamerC-09 & CTCACCGTCC \\
\hline 3 & GL DecamerA-07 & GAAACGGGTG & 13 & GL DecamerC-10 & TGTCTGGGTG \\
\hline 4 & GL DecamerA-08 & GTGACGTAGG & 14 & GL DecamerC-11 & AAAGCTGCGG \\
\hline 5 & GL DecamerA-10 & GTGATCGCAG & 15 & GL DecamerC-14 & TGCGTGCTTG \\
\hline 6 & GL DecamerA-11 & CAATCGCCGT & 16 & GL DecamerC-15 & GACGGATCAG \\
\hline 7 & GL DecamerA-13 & CAGCACCCAC & 17 & GL DecamerC-16 & CACACTCCAG \\
\hline 8 & GL DecamerA-14 & TCTGTGCTGG & 18 & GL DecamerC-17 & TTCCCCCCAG \\
\hline 9 & GL DecamerA-16 & AGCCAGCGAA & 19 & GL DecamerC-19 & GTTGCCAGCC \\
\hline 10 & GL DecamerA-17 & GACCGCTTGT & 20 & GL DecamerC-20 & ACTTCGCCAC \\
\hline
\end{tabular}

\begin{tabular}{|c|c|c|c|}
\hline Sr. No & Primer & Sequence (Forward) & Sequence (Reverse) \\
\hline 1 & SMs001 & GGTTTGTTACTCTACTCCCGT & GGCTTATCTTCCTTGCTGT \\
\hline 2 & $\mathrm{SMs} 002$ & TGAGCAAAGAAAGAGAAGTAGTC & CATCCTCCAAGCATCTGT \\
\hline 3 & SMs003 & CATCTGCTCCСТCTTCCT & CTCTGCGGCTTGGTCCTG \\
\hline 4 & SMs004 & GTTACCАTCCCАTCCCAC & AGACTGCTGCTCAATGTTC \\
\hline 5 & SMs005 & CCGTCCCATCCATTCATC & TCGTCCCTCCCTCTCCGT \\
\hline 6 & $\mathrm{SMs} 006$ & GACTCCTGTCACCGTCTTC & ATACTTCAACCGTCTCCTCC \\
\hline 7 & SMs007 & CTAAGCAAGAACACAGGAAAG & AGCAACAGCAGAGAGCAG \\
\hline 8 & SMs008 & CTGACTAAGGAGGAAGTGGAG & GACGACGATAGATGAAACA \\
\hline 9 & SMs009 & GAGCCGCAAGGAAGCGAC & TCATACAAGCAGCAAGGATAG \\
\hline 10 & SMs100 & CTCTCTTCTCGTCTCCTCATT & GTCCTTCTTCTTCTCGTGGT \\
\hline 11 & SMs011 & ACACGCATCGCAAGAAGG & AAGAACACTCAACAGAAGCAC \\
\hline 12 & $\mathrm{SMs} 012$ & AAATGTCTTCGCACTAACC & AAGGAGATGCTGATGGAGA \\
\hline 13 & SMs013 & CGTCTCCTCTTCCTCCTC & TCGTCTTTACTTGCTCGG \\
\hline 14 & SMs015 & CTACACATCTCCATTCCACAG & GGCTCCTCCTACTCGTTC \\
\hline 15 & $\mathrm{SMs} 016$ & TCTGTCCTCTGGTAATCCTG & AGCACGGCACGCAATCAC \\
\hline 16 & $\mathrm{SMs} 026$ & AGAGCCAAAGAAACAACAAA & TTCCACCTCCACTTCATC \\
\hline 17 & $\mathrm{SMs} 030$ & TACATACAAACAAGCAGCAAC & GCCAGGTAGAAGAAACAAGAG \\
\hline 18 & $\mathrm{SMs} 032$ & CGACGAGAGCCTGACGAG & AGATGGAACAAGGAGAATG \\
\hline 19 & $\mathrm{SMs} 033$ & ACGGGCGGGAAGACGAAA & ACCTGTATGGACTGGAGGA \\
\hline 20 & $\mathrm{SMs} 037$ & AGTTGTAAGTCGTTCTGGTTT & TTTGGGCAGTCGTTTATC \\
\hline 21 & SMs036 & СТСТCTCTTTGCTGCGGG & CTTCCTTGGGATTTAGTGTC \\
\hline 22 & $\mathrm{SMs} 037$ & AGTTGTAAGTCGTTCTGGTTT & TTTGGGCAGTCGTTTATC \\
\hline 23 & $\mathrm{SMs} 041$ & ACAGACACAGGCGGGCGA & TAGCACTCCATTCAGCAAA \\
\hline 24 & $\mathrm{SMs} 042$ & GTTTCTCCACСТCСАACTC & CCCAGTGCTTCCTCTCTC \\
\hline 25 & $\mathrm{SMs} 043$ & TATCCTCTGCGGCTCTTC & TACTTGCTGACCTTTGTTCTG \\
\hline 26 & SMs045 & GAGGAGGTGACGGTGGAG & GACGCTACGGTTCATTCA \\
\hline 27 & SMs048 & ATACGCTACTCTGAATCCCAC & CAATCACTATGTAAGGCAACA \\
\hline 28 & SMs049 & АСТССТСТTССТСТТССТСТТ & GTTGTTCCCGTTCCCGCC \\
\hline
\end{tabular}


For RAPD analysis, (Appendix A) and SSR studies, reaction mixtures of 25 and 20 $\mu \mathrm{L}$ were used, respectively, to amplify genomic DNA in a thermal cycler (Eppendorf DNA Thermal Cycler 9600). RAPD amplicons were separated on 1.2\% (w/v) agarose gels, whereas SSR products were analyzed using a 3\% (w/v) Metaphor gel (high-resolution agarose), stained with ethidium bromide.

Data from RAPD and SSR gels were recorded by denoting the presence of each locus as 1 and absence as 0 . The polymorphic information content (PIC) values were calculated as suggested by Cordeiro et al. (2001). The coefficient of similarity was calculated according to Nei and Li (1979) using the NTSYSpc (version 2.1) cluster analysis software (Exeter Software Co., Setauket, NY). A dendrogram based on these similarity coefficients was constructed using the unweighted pair group method with arithmetic mean (UPGMA) algorithm (Sneath and Sokal, 1973), provided in the package NTSYSpc software (Rohlf, 1993).

\section{RESULTS AND DISCUSSION}

\section{Callogenesis}

The present investigation revealed that there is a wide variation in callus texture and color and degree of callus formation depending on culture medium formulation, explant source and genotype. In the present study, two prominent callus types were observed, i.e., compact (embryogenic) and friable (non-embryogenic), based on their morphological appearance. Such a highly diversified mixture of callus in sugarcane was also reported by Brisibe et al. (1994), Falco et al. (1996) and Anbalagan et al. (2000). Anbalagan et al. (2000), while working on sugarcane cultivars, reported the formation of two types of calli from leaf explant. They found that one was loose, friable and non-embryogenic (non-regenerable), and the other was compact, white, nodular and embryogenic (regenerable). The callus was so heterogeneous in texture that there was still considerable confusion with regard to its nomenclature.

The results of the present study also showed that a wide range of variation exists in degree of callus formation (Table 4) and callus induction. Callus initiation on cut ends of in vitro cultured explants was observed in all hormonal combinations. The explants cultured on MS medium without growth regulators did not produce any callus and was excluded while studying the comparison of different concentrations of growth regulators.

\begin{tabular}{|c|c|c|c|c|c|c|c|c|}
\hline \multirow[t]{3}{*}{ Hormone concentration } & \multicolumn{4}{|c|}{$\mathrm{MS}+2,4-\mathrm{D}$} & \multicolumn{4}{|c|}{$\mathrm{MS}+\mathrm{IAA}$} \\
\hline & \multicolumn{2}{|c|}{ Callus induction* (\%) } & \multicolumn{2}{|c|}{ Callus formation** } & \multicolumn{2}{|c|}{ Callus induction* (\%) } & \multicolumn{2}{|c|}{ Callus formation** } \\
\hline & Leaf & Pith & Leaf & Pith & Leaf & Pith & Leaf & Pith \\
\hline $1.0 \mathrm{mg} / \mathrm{L}$ & 93.33 & 86.67 & $2.18 \pm 0.12$ & $1.45 \pm 0.31$ & 60.00 & 50.00 & $1.13 \pm 0.19$ & $0.70 \pm 0.74$ \\
\hline $3.0 \mathrm{mg} / \mathrm{L}$ & 96.67 & 83.33 & $2.94 \pm 0.22$ & $2.15 \pm 0.45$ & 90.00 & 66.67 & $1.60 \pm 0.11$ & $1.03 \pm 0.64$ \\
\hline $5.0 \mathrm{mg} / \mathrm{L}$ & 90.00 & 73.33 & $2.20 \pm 0.08$ & $1.38 \pm 0.26$ & 93.33 & 73.33 & $1.80 \pm 0.22$ & $1.15 \pm 0.59$ \\
\hline $7.0 \mathrm{mg} / \mathrm{L}$ & 83.33 & 63.33 & $1.55 \pm 0.14$ & $1.03 \pm 0.02$ & 96.67 & 80.00 & $2.03 \pm 0.25$ & $1.88 \pm 0.36$ \\
\hline $9.0 \mathrm{mg} / \mathrm{L}$ & 73.33 & 56.67 & $1.50 \pm 0.11$ & $0.83 \pm 0.08$ & 90.00 & 86.67 & $2.55 \pm 0.12$ & $1.38 \pm 0.36$ \\
\hline Leaf mean & 87.33 & & $2.07 \pm 0.26$ & & 86.00 & & $1.82 \pm 0.23$ & \\
\hline Pith mean & 72.67 & & $1.37 \pm 0.23$ & & 71.33 & & $1.23 \pm 0.22$ & \\
\hline Variety mean & 80.00 & & $1.72 \pm 0.20$ & & 78.66 & & $1.53 \pm 0.17$ & \\
\hline
\end{tabular}

*Data are $\%$ of 30 replications; **Mean of 30 replications \pm standard error. MS $=$ Murashige and Skoog medium; 2,4-D $=2,4$ dichlorophenoxy acetic acid; IAA $=$ indole acetic acid. 


\section{Callogenesis in response to 2,4-D in MS medium}

The effect of 2,4-D on callus induction and formation was evaluated; the maximum degree of callus formation was $2.94 \pm 0.22$ at $3.0 \mathrm{mg} / \mathrm{L}$ with leaf explant. The maximum response by pith explant was also at $3.0 \mathrm{mg} / \mathrm{L} 2,4-\mathrm{D}$ with a callus scale of $2.15 \pm 0.45$. These findings are in line with those of Michael (2007) and Khan et al. (2008, 2009). The results also indicated that lower levels of 2,4-D performed better and produced a good callus compared to higher concentrations. Callus formation rate declined with an increase in hormone level (Table 4).

The extent of callus induction at five different 2,4-D doses using two explants is given in Table 4. Callus initiation was observed at all levels of 2,4-D in both explants; however, it varied with the medium used and the explant source, ranging from 73.33 to $96.67 \%$ with leaf and from 56.67 to $86.67 \%$ with pith explant. The highest callus induction rate, i.e., $96.67 \%$, was noted on leaf explants with $3.0 \mathrm{mg} / \mathrm{L}$ 2,4-D. Gill et al. (2002) and Badawy et al. (2008) have also reported similar results. Using pith as explants, the highest callus induction rate, i.e., $86.67 \%$, was recorded at $1.0 \mathrm{mg} / \mathrm{L}$ and the lowest $(56.67 \%)$ at $9.0 \mathrm{mg} / \mathrm{L}$. In the present study, pith was found to be less responsive with regard to callogenesis both for callus induction rate $(72.67 \%)$ and callus formation $(1.37 \pm 0.23)$, compared to leaf with regard to callus induction rate $(87.33 \%)$ and degree of callus formation $(2.07 \pm 0.26)$. It might have been due to the formation of polyphenols in pith cultures, which resulted in poor callus formation. Our results are in accordance with the findings of Aftab and lqbal (1999) and Snyman et al. (2001).

\section{Callogenesis in response to IAA in MS medium}

The effect of IAA on callus induction and formation was also studied, and it was observed that leaf explant performed better at the $9.0 \mathrm{mg} / \mathrm{L}$ dose of IAA with a callus formation score of $2.55 \pm 0.12$, followed by $7.0 \mathrm{mg} / \mathrm{L}$ (callus formation $=2.03 \pm 0.25$ ). Callus formation was significantly reduced by decreasing the IAA concentration. Minimum callus formation $(1.13 \pm 0.19)$ was recorded at a concentration of $1.0 \mathrm{mg} / \mathrm{L}$. Pith explant produced maximum callus at $7.0 \mathrm{mg} / \mathrm{L}$ with a callus formation score of $1.88 \pm 0.36$, followed by $1.38 \pm 0.36$ at $9.0 \mathrm{mg} / \mathrm{L}$. Minimum callus formation $(0.70 \pm 0.74)$ was recorded at $1.0 \mathrm{mg} / \mathrm{L}$ IAA. Leaf as explant source produced a maximum score of $1.82 \pm 0.23$. The effect of explant source was obvious by this assessment (Table 4).

It was evident from the above findings that higher levels of IAA proved more effective than lower concentrations. Wen and Kinsella (1991) reported similar findings. Leaf as explant source proved to be a better callus producer than pith. These results are also in line with previously reported findings (Shahid et al., 1994; Javed et al., 2001). On average, IAA-containing medium produced a callus formation score of $1.53 \pm 0.17$, which is less than that obtained with 2,4-D (1.72 \pm 0.20$)$ as auxin. This could be the reason why 2,4-D has been used by many research workers (Mannan and Amin, 1999; Prajapati et al., 2000; Hanafy et al., 2007).

Callus induction with two explant types at different concentrations of IAA was also investigated. Callus initiation was observed with all treatments in both explants, but the rates differed. Callogenic response by leaf explant was between 60.0 and $96.67 \%$ and by pith explant from 50.0 to $86.67 \%$ (Table 4 ).

The highest callus initiation response by leaf explants was with $7.0 \mathrm{mg} / \mathrm{L} \mathrm{IAA}(96.67 \%)$, followed by $9.0 \mathrm{mg} / \mathrm{L}$ IAA (90.0\%). Minimum callus induction, i.e., $60.0 \%$, was recorded at 1.0 $\mathrm{mg} / \mathrm{L}$ IAA. Using pith explants, a maximum of $86.67 \%$ cultures developed calli at $9.0 \mathrm{mg} / \mathrm{L}$ fol- 
lowed by callus induction of $80.0 \%$ at $7.0 \mathrm{mg} / \mathrm{L} \mathrm{IAA}$, whereas minimum callus induction $(50.0 \%)$ was recorded at a dose of $1.0 \mathrm{mg} / \mathrm{L}$. These findings showed that callus induction rate increased with increase in IAA concentration in the medium. The results also indicated that callus induction was greater with the leaf as explant source (86.0\%) compared to pith explant $(71.33 \%)$.

\section{Organogenesis, regeneration of micro-shoots}

Calli developed by leaf explant when cultured on MS + 2,4-D as auxin, produced maximum shoots on MS medium supplemented with $1.0 \mathrm{mg} / \mathrm{L}$ kinetin (Table 5) and $90 \%$ cultures initiated shoot emergence. The average number of shoots obtained per test tube was $21.00 \pm 0.86$. It was followed by $0.5 \mathrm{mg} / \mathrm{L}$ kinetin, which produced $15.80 \pm 0.50$ shoots with $80 \%$ shoot induction. Low levels of cytokinin (kinetin) to regenerate sugarcane calli was also used by Javed et al. (2001), Ali et al. (2008) and Ather et al. (2009).

\begin{tabular}{|c|c|c|c|c|c|c|c|c|}
\hline \multirow[t]{3}{*}{ MS + kinetin } & \multicolumn{4}{|c|}{ Calli developed using 2,4-D as auxin } & \multicolumn{4}{|c|}{ Calli developed using IAA as auxin } \\
\hline & \multicolumn{2}{|c|}{ Leaf explant } & \multicolumn{2}{|c|}{ Pith explant } & \multicolumn{2}{|c|}{ Leaf explant } & \multicolumn{2}{|c|}{ Pith explant } \\
\hline & $\begin{array}{c}\text { Regen- } \\
\text { eration* }(\%)\end{array}$ & $\begin{array}{l}\text { Number of } \\
\text { shoots** }\end{array}$ & $\begin{array}{c}\text { Regen- } \\
\text { eration* }(\%)\end{array}$ & $\begin{array}{l}\text { Number of } \\
\text { shoots** }\end{array}$ & $\begin{array}{c}\text { Regen- } \\
\text { eration* }(\%)\end{array}$ & $\begin{array}{l}\text { Number of } \\
\text { shoots** }\end{array}$ & $\begin{array}{c}\text { Regen- } \\
\text { eration* }(\%)\end{array}$ & $\begin{array}{l}\text { Number of } \\
\text { shoots** }\end{array}$ \\
\hline $0.1 \mathrm{mg} / \mathrm{L}$ & 70 & $06.10 \pm 0.25$ & 60 & $2.46 \pm 0.14$ & 50 & $5.83 \pm 0.24$ & 40 & $2.43 \pm 0.15$ \\
\hline $0.5 \mathrm{mg} / \mathrm{L}$ & 80 & $15.80 \pm 0.50$ & 70 & $3.66 \pm 0.21$ & 60 & $6.94 \pm 0.25$ & 50 & $3.40 \pm 0.14$ \\
\hline $1.0 \mathrm{mg} / \mathrm{L}$ & 90 & $21.00 \pm 0.86$ & 80 & $7.23 \pm 0.35$ & 80 & $6.10 \pm 0.16$ & 50 & $3.96 \pm 0.22$ \\
\hline $1.5 \mathrm{mg} / \mathrm{L}$ & 100 & $08.66 \pm 0.43$ & 60 & $6.51 \pm 0.24$ & 70 & $4.16 \pm 0.13$ & 50 & $2.90 \pm 0.14$ \\
\hline $2.0 \mathrm{mg} / \mathrm{L}$ & 80 & $03.76 \pm 0.56$ & 60 & $3.17 \pm 0.29$ & 50 & $3.91 \pm 0.62$ & 40 & $2.72 \pm 0.83$ \\
\hline Mean & 84 & 11.06 & 66 & 4.60 & 62 & 5.38 & 46 & 3.08 \\
\hline Mean square & & $134.23 * *$ & & $15.49 * *$ & & $3.60 * * *$ & & $1.29 * * *$ \\
\hline
\end{tabular}

For explanations, see legend to Figure 4.

Calli obtained on MS + 2,4-D using pith explant when cultured on regeneration media produced an average of $7.23 \pm 0.35$ shoots per test tube at $1.0 \mathrm{mg} / \mathrm{L}$ kinetin and $80 \%$ cultures responded with regeneration, followed by $1.5 \mathrm{mg} / \mathrm{L}$ kinetin, giving $6.51 \pm 0.24$ shoots with $60 \%$ cultures showing organogenesis. This indicates that leaf-based calli are more meristematic and more morphogenic compared to pith source calli. Similar results were found in previous studies by many workers (Shaheen and Mirza, 1989; Shahid et al., 1990; Rahman et al., 2003).

Performance of leaf calli produced using IAA in media, generated $6.94 \pm 0.25$ shoots per test tube and $60 \%$ cultures responded with regeneration in a medium containing $0.5 \mathrm{mg} / \mathrm{L}$ kinetin, followed by $1.0 \mathrm{mg} / \mathrm{L}$ kinetin where the average number of shoots was $6.10 \pm 0.16$ and $80 \%$ cultures showed regeneration (Table 5).

Performance of pith calli produced in the medium containing IAA, generated $3.96 \pm$ 0.22 shoots per test tube and $50 \%$ cultures responded with regeneration in medium containing $1.0 \mathrm{mg} / \mathrm{L}$ kinetin, followed by $0.5 \mathrm{mg} / \mathrm{L}$ kinetin, where the average number of shoots produced was $3.40 \pm 0.14$ and 50\% cultures showed regeneration (Table 5). This indicates that the regeneration ability of calli developed with 2,4-D-suppplemented MS medium was much better than with IAA-containing medium. Based on these results, it may be concluded that callus tissue cells produced in the presence of 2,4-D were more receptive to kinetin for shoot formation. Calli obtained from pith explants produced in the media containing 2,4-D and IAA showed less morphogenic response compared to leaf explants. It may be due to the formation of non-morphogenic callus from pith explant source. 
The elongated shoots ( $<4 \mathrm{~cm}$ long) were transferred to rooting medium for root induction. In vitro induction of roots in the regenerated shoots was studied in full- and half-strength MS medium supplemented with five different concentrations of IBA or NAA. Root induction was observed at all five concentrations of IBA and NAA with half- and full-MS media. However, rooting response varied with basal medium strength and auxin concentrations. Frequency of root formation was different in all treatments.

It was observed that $65 \%$ of shoots established roots with a mean of $6.75 \pm 0.76$ roots at $1.5 \mathrm{mg} / \mathrm{L}$ IBA in full-strength MS medium, whereas $60 \%$ root induction with $6.45 \pm 0.52$ roots in half-strength MS medium at the same concentration of IBA. When NAA was added to full- and half-strength MS medium, the best response was seen with a concentration of $1.5 \mathrm{mg} / \mathrm{L}$, producing 50 and $55 \%$ root induction and $6.45 \pm 0.77$ and $5.14 \pm 0.35$ roots, respectively (Table 6 ). Many investigators have used IBA at lower concentrations for root induction (Baksha et al., 2002; Khatun et al., 2003; Sabaz et al., 2008). Mean values shown in Table 6 indicate that half-strength MS medium when supplemented with IBA and NAA produced 4.51 and 4.34 roots, respectively. These values are higher than the number of roots produced when full-strength MS medium was used for root culture. The results are in line with the findings of Khadiga et al. (2009).

\begin{tabular}{|c|c|c|c|c|c|}
\hline \multirow[t]{2}{*}{ Genotype } & \multirow[t]{2}{*}{ Concentration (mg/L) } & \multicolumn{2}{|c|}{ Full MS } & \multicolumn{2}{|c|}{$1 / 2 \mathrm{MS}$} \\
\hline & & Response $(\%)^{\mathrm{Y}}$ & No. of roots ${ }^{2}$ & Response $(\%)^{\mathrm{Y}}$ & No. of roots ${ }^{2}$ \\
\hline \multicolumn{6}{|c|}{ Root development in MS and $1 / 2$ MS medium supplemented with IBA } \\
\hline S97US297 & $\begin{array}{l}0.5 \\
1.0 \\
1.5 \\
2.0 \\
2.5\end{array}$ & $\begin{array}{l}40 \\
60 \\
65 \\
30 \\
25 \\
44\end{array}$ & $\begin{array}{c}4.25 \pm 0.51 \\
5.35 \pm 0.68 \\
6.75 \pm 0.76 \\
3.25 \pm 0.55 \\
2.50 \pm 0.24 \\
4.42\end{array}$ & $\begin{array}{l}30 \\
45 \\
60 \\
50 \\
30 \\
43\end{array}$ & $\begin{aligned} & 3.26 \pm 0.51 \\
& 4.05 \pm 0.65 \\
& 6.45 \pm 0.52 \\
& 5.35 \pm 0.54 \\
& 3.45 \pm 0.72 \\
& 4.51\end{aligned}$ \\
\hline \multicolumn{6}{|c|}{ Root development in MS and $1 / 2$ MS medium supplemented with NAA } \\
\hline S97US297 & $\begin{array}{l}0.5 \\
1.0 \\
1.5 \\
2.0 \\
2.5\end{array}$ & $\begin{array}{l}30 \\
45 \\
50 \\
40 \\
35 \\
40\end{array}$ & $\begin{array}{l}2.42 \pm 0.45 \\
5.43 \pm 0.66 \\
6.45 \pm 0.77 \\
3.08 \pm 0.45 \\
2.45 \pm 0.22 \\
\quad 3.96\end{array}$ & $\begin{array}{l}25 \\
45 \\
55 \\
35 \\
24 \\
36.8\end{array}$ & $\begin{aligned} & 3.22 \pm 0.55 \\
& 4.68 \pm 0.76 \\
& 5.14 \pm 0.35 \\
& 4.35 \pm 0.54 \\
& 4.34 \pm 0.67 \\
& 4.34\end{aligned}$ \\
\hline
\end{tabular}

X Rated after 30 days of culture; ${ }^{\mathrm{Y}}$ Mean of 20 replications; ${ }^{\mathrm{Z}}$ Mean of 20 replications \pm standard error. MS $=$ Murashige and Skoog medium (full- and half-strength MS medium); IBA = indole-3-butyric acid; NAA = 1-naphthaleneacetic acid.

A total of 627 plantlets (somaclones) produced were transplanted in the field after hardening under greenhouse conditions. These somaclones were evaluated for their resistance against red rot using their own pathotype by the bore hole method for three consecutive generations. Only those progeny in which inocula did not cross the adjacent nodes were declared resistant. Fifteen somaclones that showed resistance were used in the molecular studies.

\section{Molecular studies}

DNA-based markers were also used to assess variability among 15 somaclones and their parent genotype S97US297. In the present study, two types of markers, RAPD and SSR, were used. The results are described below. 


\section{RAPD polymorphism in somaclones and their parent S97US297}

In total, 100 RAPD primers were used, of which 20 were found to be polymorphic. The polymorphic primers generated 79 DNA fragments. Of 79 bands, 31 were polymorphic, while 48 were monomorphic, depicting $39.24 \%$ polymorphism (Table 7 ). Thus, the average number of bands produced by each primer was 3.95. The size of the amplification products ranged from 250 to $700 \mathrm{bp}$. The maximum number of bands (7) was produced by the primer GLA-08 and GLA-16, followed by primer GLA-13 (6), whereas the minimum number (2) of bands was produced by the primers GLC-09, GLC-15 and GLC-16. Primer GLA-02 depicted maximum $(66.66 \%)$ polymorphism, followed by primer GLA-14 with $60.0 \%$ polymorphism. Primer GLA-13 was the least polymorphic with $16.67 \%$ polymorphism.

\begin{tabular}{|c|c|c|c|c|c|c|}
\hline Sr. No. & Primer & Band size & Total bands & Polymorphic bands & $\%$ Polymorphic & PIC \\
\hline 1 & GLA-02 & $300-600$ & 3 & 2 & 66.66 & 0.28 \\
\hline 2 & GLA-03 & $300-600$ & 4 & 2 & 50.00 & 0.24 \\
\hline 3 & GLA-07 & $250-600$ & 4 & 2 & 50.00 & 0.22 \\
\hline 4 & GLA-08 & $250-600$ & 7 & 2 & 28.57 & 0.16 \\
\hline 5 & GLA-10 & $300-500$ & 3 & 1 & 33.33 & 0.22 \\
\hline 6 & GLA-11 & $300-600$ & 4 & 2 & 50.00 & 0.32 \\
\hline 7 & GLA-13 & $300-600$ & 6 & 1 & 16.67 & 0.15 \\
\hline 8 & GLA-14 & $300-700$ & 5 & 3 & 60.00 & 0.20 \\
\hline 9 & GLA-16 & $250-650$ & 7 & 2 & 28.57 & 0.18 \\
\hline 10 & GLA-17 & $350-650$ & 4 & 1 & 25.00 & 0.14 \\
\hline 11 & GLA-20 & $350-600$ & 4 & 2 & 50.00 & 0.32 \\
\hline 12 & GLC-09 & $300-500$ & 2 & 1 & 50.00 & 0.26 \\
\hline 13 & GLC-10 & $300-600$ & 4 & 2 & 50.00 & 0.12 \\
\hline 14 & GLC-11 & $400-550$ & 4 & 1 & 25.00 & 0.06 \\
\hline 15 & GLC-14 & $400-650$ & 3 & 1 & 33.33 & 0.35 \\
\hline 16 & GLC-15 & $350-500$ & 2 & 1 & 50.00 & 0.40 \\
\hline 17 & GLC- 16 & $300-500$ & 2 & 1 & 50.00 & 0.22 \\
\hline 18 & GLC-17 & $250-600$ & 4 & 1 & 25.00 & 0.34 \\
\hline 19 & GLC-19 & $350-650$ & 4 & 2 & 50.00 & 0.45 \\
\hline 20 & GLC-20 & $300-600$ & 3 & 1 & 33.33 & 0.28 \\
\hline Total & & & $79(\sim 3.95)$ & 31 & & \\
\hline
\end{tabular}

$\mathrm{PIC}=$ polymorphic information content.

PIC is directly correlated with the allelic diversity at a given locus that can be detected per marker in a set of individuals. The PIC value is the discriminatory power of the primer used; it describes the capacity of the primer to exploit polymorphism. The PIC value ranged from 0.06 to 0.45 (Table 7). A maximum PIC value of 0.45 was shown by the RAPD primer GLC-19, followed by the primer GLC-15 with 0.40 . It is possible that other primers could yield a higher level of PIC. The RAPD technique has been used by many scientists to detect somaclonal variation in sugarcane (Taylor et al., 1995; Saini et al., 2004; Jain et al., 2005; Suprasanna et al., 2006, 2007; Devarumath et al., 2007). Nair et al. (2002) investigated genetic diversity in 28 prominent Indian sugarcane varieties with $63.74 \%$ polymorphism using 25 RAPD markers. Lal et al. (2008) determined variability using 16 RAPD primers and amplified a total of 110 scorable fragments in sugarcane genotype CoSe 01235 with an average of 6.5 bands per primer and 96 scorable loci in CoSe 01424 with an average of 6.0 bands per primer. The PIC value observed by Wang et al. (2009) was 0.36 . The PIC values observed by Hu et al. (2009) were 0.28-0.98 (average $=0.79)$.

Data exhibited in Table 8 indicate that the mean genetic similarity among the soma- 
M.T.H. Shahid et al.

1840

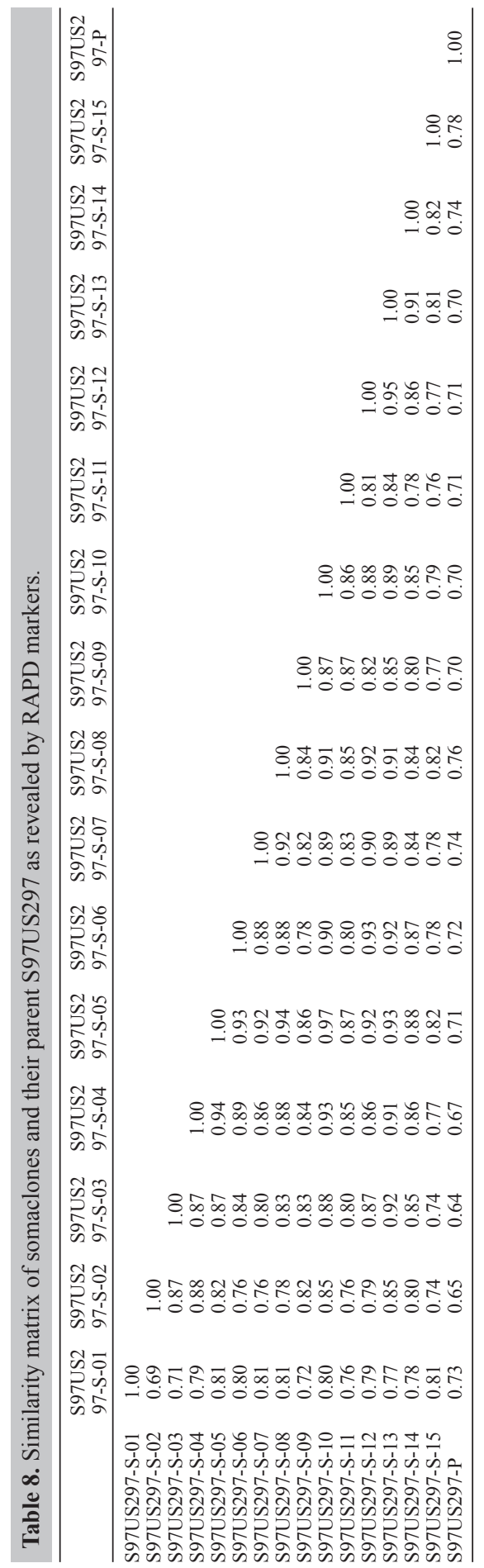


clones derived from parent S97US297 is $82.48 \%$ (0.64-0.97), which shows that the somaclones are similar for a large part of the genome. This may be due to the fact that somaclones had been developed from the same parent. The greatest similarity, 97.0\%, was recorded between the somaclones S97US297-S-05 and S97US297-S-10, followed by similarity indices of 95.0\% between the somaclones S97US297-S-12 and S97US297-S-13.

The somaclone S97US297-S-03 had the least genetic similarity (0.64) with the parent genotype. S97US297-S-15 had maximum similarity (0.78) with the parent S97US297 (P) followed by S97US297-S-08 with a similarity index of 0.76 . From the similarity matrix, it can be concluded that somaclone S97US297-S-03 differs the most from the parent compared to the other somaclones. This provides evidence of the occurrence of maximum genetic changes in this clone while passing through in vitro culture.

A dendrogram of fifteen somaclones and their parent S97US297 (Figure 1) was constructed based on the genetic similarity matrix generated from the 79 RAPD loci amplified by 20 primers. On the basis of clustering pattern at similarity index of 0.80 , somaclones may be divided into three groups.

Somaclones S97US297-S-01 and S97US297-S-15 formed the most dissimilar pair, which occupied Cluster 1. Cluster 2 consisted of the maximum number of somaclones, i.e., 13. This cluster was divided into further subclusters. Somaclones S97US297-S-02 and S97US297S-03; S97US297-S-9 and S97US297-S-11 formed the second most dissimilar pairs of somaclones. Somaclones S97US297-S-05 and S97US297-S-10 were the most similar somaclones, whereas somaclones S97US297-S-12 and S97US297-S-13 were the second most similar pair. Parental genotype S97US297 was the most divergent from all the somaclones with a similarity index of 0.71. It alone occupied Cluster 3.

Clustering and subclustering, as depicted in the dendrogram, demonstrated the induction of variability at the DNA level through somaclonal variation. The data obtained in this study also confirmed the efficiency of the RAPD technique for determination of genetic distances and relatedness among different sugarcane somaclones. RAPD analysis has been found to be a valuable DNA marker system to evaluate genetic diversity, and it may be very useful in breeding for early identification of the most diverse clones in a large population. In view of the useful information about the close genetic relationship, it is believed that goal-oriented breeding programs with the help of somaclonal variation will enhance the production of distinct genotypes with diverse genetic background and improve crop productivity.

\section{SSR polymorphism in somaclones and their parent S97US297}

In total, 50 SSR primers were used, of which 28 were found to be polymorphic. A total of 49 bands were generated by these 28 SSR primers (Table 9 ).

Of 49 bands, 33 bands were polymorphic, showing $67.34 \%$ polymorphism. The average number of bands produced by each primer was 1.75 . The size of the amplification products ranged from 100 to $1400 \mathrm{bp}$. The maximum number of bands (9) was produced by the primer SMs006, whereas 17 primers produced a single polymorphic band. Primer SMs008 was the least polymorphic, with $33.33 \%$ polymorphism. Jannoo et al. (2001) reported a high level of heterozygosity in Mauritius sugarcane germplasm. They studied diversity in 96 genotypes with just two primer pairs.

Cordeiro et al. (2001) applied 21 primer sets to five sugarcane genotypes, and among 


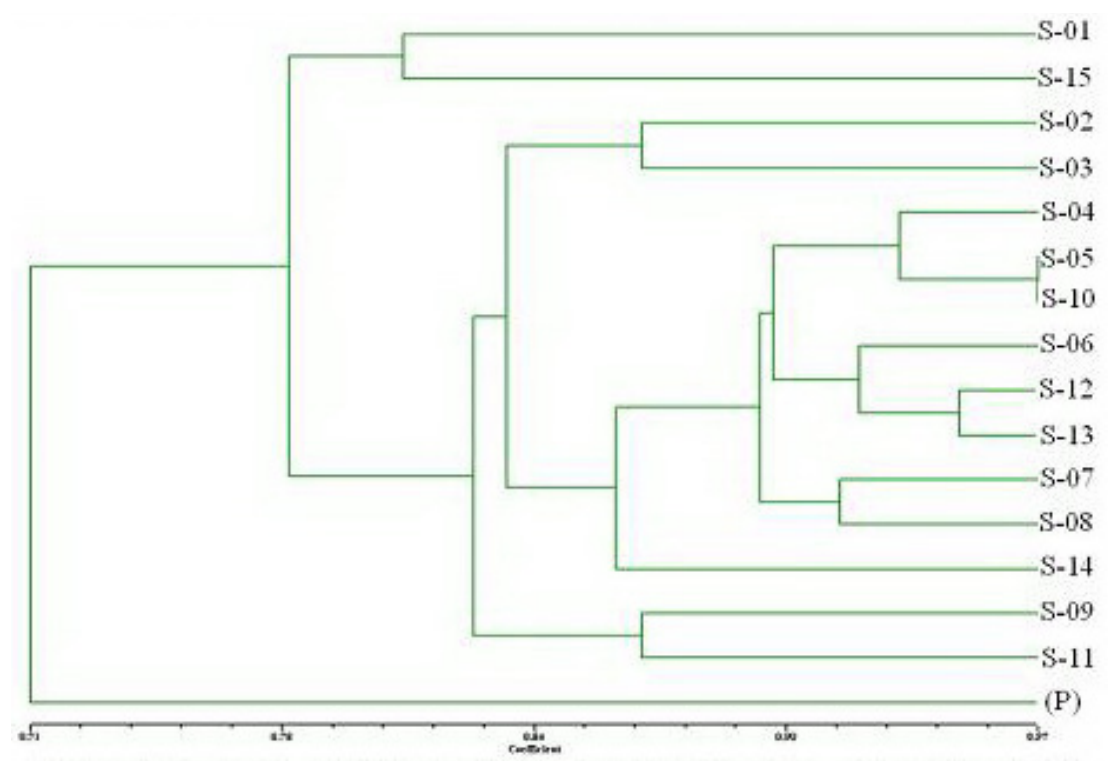

Figure 1. Dendrogram of somaclones and their parent S97US297 as revealed by RAPD markers. S-01 = S97US297-S-01; S-02 = S97US297-S-02; S-03 = S97US297-S-03; S-04=S97US297-S-04; S-05=S97US297-S-05; S-06 = S97US297-S-06; S-07 = S97US297-S-07; S-08 = S97US297-S-08; S-09 = S97US297-S-09; S-10 = S97US297-S-10; S-11 = S97US297-S-11; S-12=S97US297-S-12; S-13=S97US297-S-13; S-14=S97US297-S-14; S-15 = S97US297-S-15; S97US297 = Parent.

Table 9. Polymorphism in somaclones and their parent 'S97US297' as revealed by SSR markers.

\begin{tabular}{|c|c|c|c|c|c|c|}
\hline Sr. No. & Primer & Band size & Total bands & Polymorphic bands & $\%$ Polymorphic & PIC \\
\hline 1 & SMs002 & 1000 & 1 & 1 & 100.00 & 0.30 \\
\hline 2 & $\mathrm{SMs} 004$ & 200 & 1 & 1 & 100.00 & 0.22 \\
\hline 3 & SMs006 & $100-1400$ & 9 & 4 & 44.44 & 0.30 \\
\hline 4 & SMs008 & $500-700$ & 3 & 1 & 33.33 & 0.30 \\
\hline 5 & SMs009 & $200-300$ & 2 & 1 & 50.00 & 0.17 \\
\hline 6 & SMs010 & 500 & 1 & 1 & 100.00 & 0.38 \\
\hline 7 & SMs011 & 400 & 1 & 1 & 100.00 & 0.30 \\
\hline 8 & SMs012 & $200-900$ & 2 & 1 & 50.00 & 0.38 \\
\hline 9 & SMs013 & 500 & 1 & 1 & 100.00 & 0.30 \\
\hline 10 & SMs015 & 750 & 1 & 1 & 100.00 & 0.22 \\
\hline 11 & SMs016 & 900 & 1 & 1 & 100.00 & 0.38 \\
\hline 12 & SMs018 & 100 & 1 & 1 & 100.00 & 0.22 \\
\hline 13 & SMs021 & 300 & 1 & 1 & 100.00 & 0.30 \\
\hline 14 & $\mathrm{SMs} 023$ & 300 & 2 & 1 & 50.00 & 0.17 \\
\hline 15 & $\mathrm{SMs} 026$ & $200-400$ & 2 & 1 & 50.00 & 0.06 \\
\hline 16 & SMs029 & 900 & 1 & 1 & 100.00 & 0.22 \\
\hline 17 & $\mathrm{SMs} 030$ & $300-500$ & 2 & 1 & 50.00 & 0.47 \\
\hline 18 & SMs032 & $300-500$ & 2 & 1 & 50.00 & 0.22 \\
\hline 19 & SMs033 & 800 & 1 & 1 & 100.00 & 0.38 \\
\hline 20 & SMs035 & $500-700$ & 4 & 3 & 75.00 & 0.36 \\
\hline 21 & SMs036 & 500 & 1 & 1 & 100.00 & 0.22 \\
\hline 22 & SMs037 & 800 & 1 & 1 & 100.00 & 0.22 \\
\hline 23 & SMs041 & $700-1000$ & 2 & 1 & 50.00 & 0.38 \\
\hline 24 & SMs042 & 650 & 2 & 1 & 50.00 & 0.12 \\
\hline 25 & SMs043 & 1400 & 1 & 1 & 100.00 & 0.30 \\
\hline 26 & SMs045 & 400 & 1 & 1 & 100.00 & 0.47 \\
\hline 27 & SMs048 & 500 & 1 & 1 & 100.00 & 0.12 \\
\hline \multirow[t]{2}{*}{28} & SMs049 & 300 & 1 & 1 & 100.00 & 0.22 \\
\hline & & & 49 & 33 & & \\
\hline
\end{tabular}

$\mathrm{PIC}=$ polymorphic information content. 
them, 17 pairs were polymorphic, but the level of polymorphism (PIC value) in the cultivars detected by these SSRs was low (0.23). Khan et al. (2009) developed tissue culture plants using young leaf of sugarcane as explant. Genetic fidelity with 10 SSR primers was studied. A total of 37 loci were amplified, of which 30 were polymorphic, indicating $81 \%$ polymorphism. The average number of loci per locus was 3.7, with a range of two to eight. The amplified product resulting from SSR primers ranged from 117 to $2191 \mathrm{bp}$. Using SSR primers, the present study showed PIC values ranging from 0.06 to 0.47 (Table 9). A maximum PIC value of 0.47 was obtained with SSR primers SMs045 and SMs030, whereas the lowest PIC (0.06) was recorded for the primer SMs026.

The mean genetic similarity among the somaclones derived from parent S97US297 was $67.62 \%$, which also shows that a large part of the genome is similar (Table 10). This may be due to the fact that the somaclones had originated from the same parent. The greatest similarity (95.0\%) was recorded between the somaclones S97US297-S-08 and S97US297S-14. The somaclone S97US297-S-02 had the maximum genetic similarity (0.91) with the parent followed by the somaclone S97US297-S-15 (0.86). The somaclones S97US297-S-03, S97US297-S-05 and S97US297-S-07 had the least genetic similarity (0.43) with the parent. Khan et al. (2009) determined a similarity coefficient matrix based on genetic distance according to Nei and $\mathrm{Li}(1979)$ to estimate the genetic divergence and relatedness among the somaclones developed, which ranged from 0.366 (P-100 vs P-98) to 0.951 (parent vs P-104).

A dendrogram was constructed using fifteen somaclones and their parent S97US297 (Figure 2) on the basis of genetic similarity matrix generated from the 49 SSR loci from 28 polymorphic primers. The clustering pattern showed that at a similarity index (coefficient) of 0.70 , the somaclones formed four clusters. Cluster 1 consisted of two somaclones, S97US297S-01 and S97US297-S-05, and Cluster 2 consisted of four somaclones, S97US297-S-03, S97US297-S-07, S97US297-S-08, and S97US297-S-14. Cluster 3 consisted of six somaclones, S97US297-S-06, S97US297-S-09, S97US297-S-10, S97US297-S-11, S97US297-S-12, and S97US297-S-13, and Cluster 4 consisted of three somaclones, S97US297-S-02, S97US297S-04, S97US297-S-15 and S97US297 (P). Somaclones S97US297-S-01 and S97US297-S-05 comprised the most dissimilar pair and occupied Cluster 1. S97US297-S-08 and S97US297S-14 were the most similar somaclones present in Cluster 2. Three pairs, namely somaclones, S97US297-S-06 with S97US297-S-13, S97US297-S-09 with S97US297-S-10, and S97US297-S-02 with S97US297 (P), were the second most similar ones. Clustering and subclustering as depicted in the dendrogram certified the presence of variability at the DNA level.

Results of SSR analysis confirmed the generation of genetic variability through somaclonal variation in sugarcane genotype S97US297. The data obtained in this study also confirmed the ability to use SSR markers for the determination and estimation of genetic similarity and dissimilarity among different sugarcane somaclones developed from the same parent. The information about genetic similarity will be helpful to create a population of genetically uniform somaclones or to select a variable somaclone with improved traits and increased productivity with respect to the parent. Like RAPD, SSR analysis may also be very useful in breeding for early identification of the most diverse clones in a large population. In this study, SSR markers proved to be better than the RAPD markers with respect to the ability to detect polymorphism, as only $39.24 \%$ polymorphism was observed by RAPD compared to $67.34 \%$ polymorphism detected through SSR. However, it is also suggested that a larger number of primers should be surveyed to get more precise results. 
M.T.H. Shahid et al.

1844

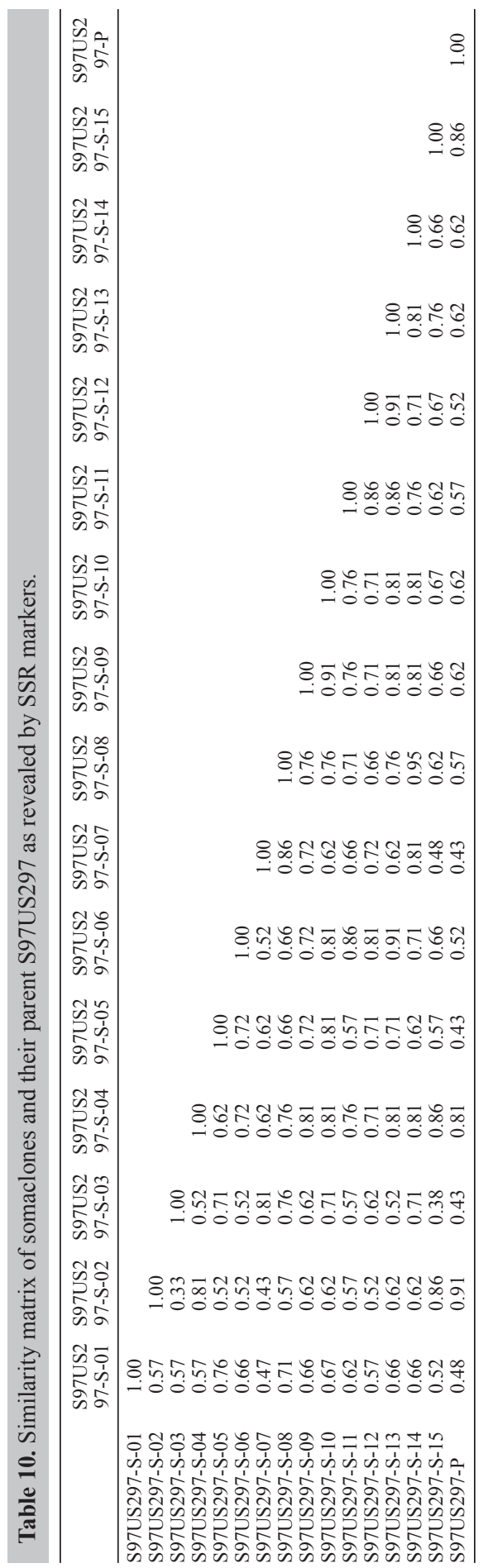




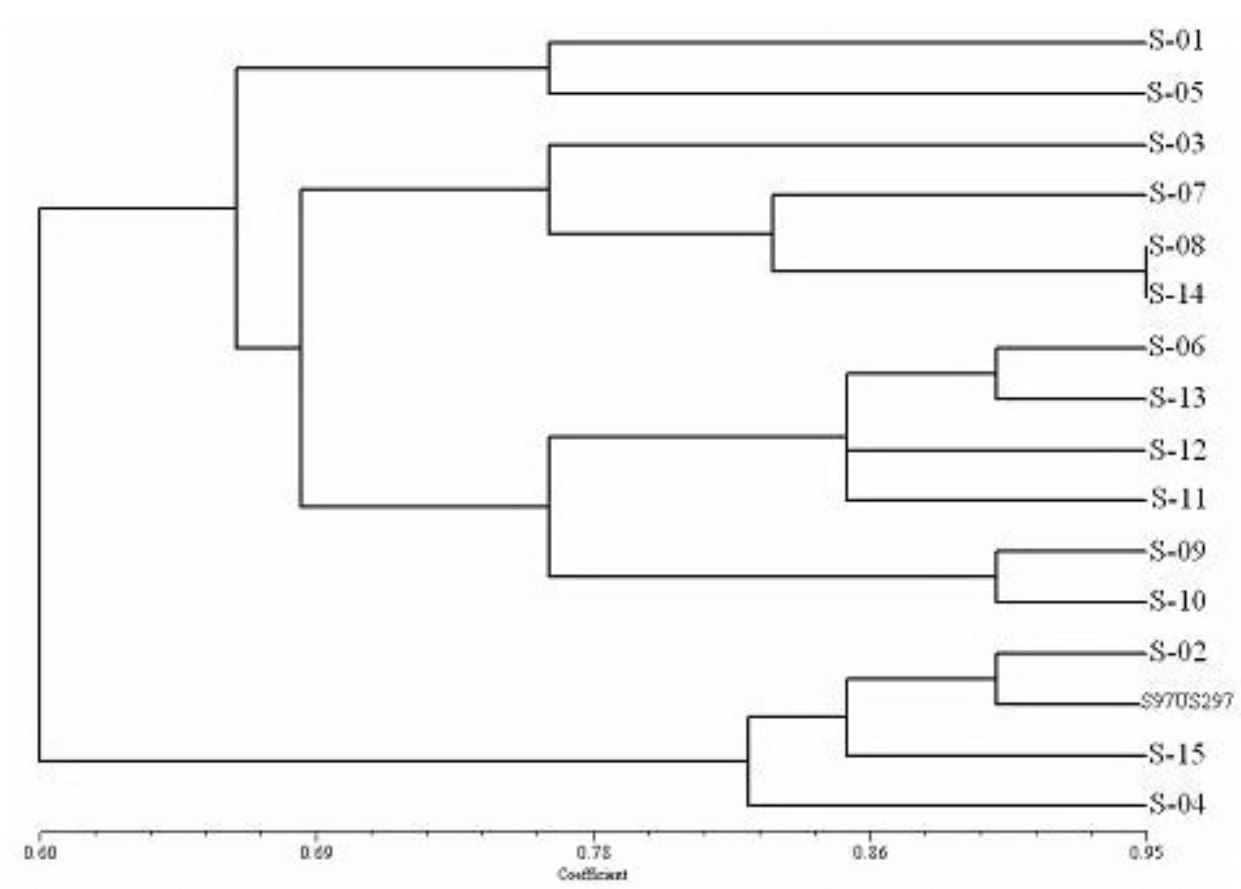

Figure 2. Dendrogram of somaclones and their parent S97US297 as revealed by SSR markers. S-01 = S97US297-S-01; S-02 = S97US297-S-02; S-03 = S97US297-S-03; S-04=S97US297-S-04; S-05 = S97US297-S-05; S-06 = S97US297-S-06; S-07 = S97US297-S-07; S-08 = S97US297-S-08; S-09 = S97US297-S-09; S-10 = S97US297-S-10; S-11 = S97US297-S-11; S-12 = S97US297-S-12; S-13 = S97US297-S-13; S-14 = S97US297-S-14; S-15 = S97US297-S-15; S97US297 = Parent.

This study identified the usefulness of somaclonal variation in generating variability in sugarcane genotype S97US297 and also ability of RAPD and SSR markers to determine the diversity among somaclones along with the parent. Very limited reports on the use of DNA markers for the estimation of somaclonal variation are available, and hence, this study should provide a benchmark for further studies.

\section{ACKNOWLEDGMENTS}

The authors acknowledge the cooperation extended by the Sugarcane Research Institute, AARI, Faisalabad, for the provision of source material and the laboratory facilities provided by the Agricultural Biotechnology Research Institute, AARI, Faisalabad, Pakistan.

\section{REFERENCES}

Aftab F and Iqbal J (1999). Plant regeneration from protoplasts derived from cell suspension of adventive somatic embryos in sugarcane (Saccharum spp. hybrid cv. CoL-54 and cv. CP-43/33). Plant Cell Tissue Organ Cult. 56: 155-162.

Ali A, Naz S, Siddiqui FA and Iqbal J (2008). Rapid clonal multiplication of sugarcane (Saccharum officinarum) through callogenesis and organogenesis. Pak. J. Bot. 40: 123-138. 
Anbalagan S, Kalamani A and Sakila M (2000). In vitro propagation of sugarcane: nature of callus, direct regeneration, regeneration through callus and morphological variations. Res. Crops 1: 138-140.

Anonymous (2008). Pakistan Economic Survey. Government of Pakistan. Available at [http://www.pro-pakistan. com/2009/06/11/download-economic-survey-of-pakistan-2008-09/]. Accessed February 26, 2010.

Ather A, Khan S, Rehman A and Nazir M (2009). Optimization of the protocols for callus induction, regeneration and acclimatization of sugarcane cv. Thatta-10. Pak. J. Bot. 41: 815-820.

Badawy OM, Nasr MI and Alhendawi RA (2008). Response of sugarcane (Saccharum species hybrid) genotypes to embryogenic callus induction and in vitro salt stress. Sugar Tech. 10: 243-247.

Baksha R, Alam R, Karim MZ, Paul SK, et al. (2002). In vitro shoot tip culture of sugar-cane (Saccharum officinarum) variety Isd 28. Biotechnology 1: 67-72.

Brisibe EA, Miyake H, Taniguchi T and Maeda E (1994). Regulation of somatic embryogenesis in long-term callus cultures of sugarcane (Saccharum officinarum L.). New Phytol. 126: 301-307.

Cordeiro GM, Casu R, McIntyre CL, Manners JM, et al. (2001). Microsatellite markers from sugarcane (Saccharum spp.) ESTs cross transferable to Erianthus and Sorghum. Plant Sci. 160: 1115-1123.

Devarumath RM, Doule RB, Kawar PG, Naikebawane SB, et al. (2007). Field performance and RAPD analysis to evaluate genetic fidelity of tissue culture raised plants vis-à-vis conventional setts derived plants of sugarcane. Sugar Tech. 9: 17-22.

Doyle JJ and Doyle JL (1990). Isolation of plant DNA from fresh tissue. Focus 12: 13-15.

Falco MC, Mendes BMJ, Tulmann NA and Gloria BA (1996). Histological characterization of in vitro regeneration of Saccharum sp. Res. Bras. Fisiol. Veg. 8: 93-97.

Gill NK, Raman G and Gosal SS (2002). Somatic embryogenesis and plant regeneration in some commercial cultivars of sugarcane. Crop Improve. 29: 28-34.

Hanafy MS and Lobna M Abou-Setta (2007). Saponins production in shoot and callus cultures of Gypsophila paniculata J. Appl. Sci. Res. 3: 1045-1049.

Hu X, Wang J, Lu P and Zhang H (2009). Assessment of genetic diversity in broomcorn millet (Panicum miliaceum L.) using SSR markers. J. Genet. Genomics 36: 491-500.

Hussnain Z and Afghan S (2006). Impact of Major Cane Diseases on Sugarcane Yield and Sugar Recovery. Annual Report, Shakarganj Sugar Research Institute, Jhang.

Jain R, Srivastava S, Singh J and Gupta PS (2005). Assessment of genetic purity of micropropagated plants of sugarcane by isozyme and RAPD analysis. Sugar Tech. 7: 15-19.

Jannoo N, Forget L and Dookun A (2001). Contribution of Microsatellites to Sugarcane Breeding Program in Mauritius. International Society of Sugar Cane Technologists, Proceedings of the XXIV Congress, Brisbane, 637-639.

Javed MA, Chaudhry BA, Tanvir MK, Shahid MTH, et al. (2001). Development and screening of sugarcane somaclones against diseases. Pak. Sugar J. 16: 36-39.

Khadiga GAE, Rasheid SM and Khalafalla MM (2009). Effect of plant growth regulators on callus induction and plant regeneration in tuber segment culture of potato (Solanum tuberosum L.) cultivar Diamant. Afr. J. Biotech. 8: 2529-2534.

Khan IA, Dahot MU, Seema N, Bibi S, et al. (2008). Genetic variability in plantlets derived from callus culture in sugarcane. Pak. J. Bot. 40: 547-564.

Khan IA, Dahot MU, Seema N, Yasmin S, et al. (2009). Genetic variability in sugarcane plantlets developed through in vitro mutagenesis. Pak. J. Bot. 41: 153-166.

Khatun MM, Ali MH and Desamero NV (2003). Effect of genotype and culture media on callus formation and plant regeneration from mature seed scutella culture in rice. Plant Tissue Cult. 13: 99-107.

Lal M, Singh RK, Srivastava S, Singh N, et al. (2008). RAPD marker based analysis of micropropagated plantlets of sugarcane for early evaluation of genetic fidelity. Sugar Tech. 10: 99-103.

Malik KB (1990). Sugarcane Production Problems and Research Strategies for Yield Improvement. Dept. Agric., Punjab.

Mannan SKA and Amin MN (1999). Callus and shoot formation from leaf sheath of sugarcane (Saccharum officinarum L.) in vitro. Indian Sugar 49: 187-192.

Menossi M, Silva-Filho MC, Vincentz M, Van-Sluys MA, et al. (2008). Sugarcane functional genomics: gene discovery for agronomic trait development. Int. J. Plant Genomics 2008: 458732.

Michael P (2007). Micropropagation of elite sugarcane planting materials from callus culture in vitro. J. Proc. Royal Soc. New South Wales 140: 79-86.

Murashige T and Skoog F (1962). A revised medium for rapid growth and bioassays with tobacco tissue cultures. Physiol. Plant. 15: 473-497.

Nair NV, Nair S, Sreenivasan TV and Mohan M (1999). Analysis of genetic diversity and phylogeny in Saccharum and related genera using RAPD markers. Gen. Res. Crop Evaluat. 46: 73-79.

Nair NV, Selvi A, Sreenivasan TV and Pushpalatha KN (2002). Molecular diversity in Indian sugarcane cultivars as revealed by randomly amplified DNA polymorphisms. Euphytica 127: 219-225. 
Nei M and Li WH (1979). Mathematical model for studying genetic variation in terms of restriction endonucleases. Proc. Natl. Acad. Sci. U. S. A. 76: 5269-5273.

Oropeza M, Guevara P, Garcia E and Ramirez JL (1995). Identification of sugarcane (Saccharum spp.) somaclonal variants resistant to surgarcane mosaic virus via RAPD markers. Plant Mol. Biol. Rep. 13: 182-191.

Powell W, Machray GC and Provan J (1996). Polymorphism revealed by simple sequence repeats. Trends Plant Sci. 1: 215-222.

Prajapati BS, Patel CL, Patel SR and Patel AA (2000). Regeneration of tissue culture plantlets through callus culture in sugarcane cultivar. Ind. J. Genet. Plant Breed. 60: 255-257.

Rahman S, Hussain M, Shahid MTH, Tanvir MK, et al. (2003). Response of different sugarcane genotypes to tissue culture. Pak. Sugar J. 18: 27-32.

Rohlf FJ (1993). NTSYS-pc numerical taxonomy and multivariate analysis system, version 2.0. Exeter software: Setauket, New York.

Sabaz AK, Rashid H, Fayyaz CM, Chaudhry Z, et al. (2008). Rapid micropropagation of three elite sugarcane (Saccharum officinarum L.) varieties by shoot tip culture. Afr. J. Biotech. 7: 2174-2180.

Saini N, Saini ML and Jain RK (2004). Large-scale production, field performance and RAPD analysis of micropropagated sugarcane plants. Indian J. Genet. Plant Breed. 64: 102-107.

Shaheen MS and Mirza MS (1989). In vitro production of plants from sugarcane tissue. Pak. J. Agri. Sci. 26: 302-312.

Shahid MTH, Shaheen MS and Mirza MS (1990). Studies on Comparative Response of Sugarcane Varieties to Callus Production. Proceedings of National Saminar on Sugarcane Production, Ayub Agricultural Research Institute, Faisalabad, 89-95.

Shahid MTH, Shaheen MS and Mirza MS (1994). Response of sugarcane varieties to plant differentiation from leaf and pith tissues. Pak. J. Agri. Res. 15: 137-143.

Siddiqui SH, Khatri A, Khan AL, Javed MA, et al. (1994). In-vitro cultures: a source of genetic variability and an aid to sugarcane improvement. Pak. J. Agric. Res. 15: 127-133.

Sneath PHA and Sokal RR (1973). Numerical Taxonomy. Freeman, San Francisco.

Snyman SJ, Hucket BI, Both FC and Watt MP (2001). A comparison of direct and indirect somatic embryogenesis, the production of transgenic sugarcane. S. Afr. J. Bot. 62: 105-107.

Suprasanna P, Desai NS, Sapna G and Bapat VA (2006). Monitoring genetic fidelity in plants derived through direct somatic embryogenesis in sugarcane by RAPD analysis. J. New Seeds 8: 1-9.

Suprasanna P, Desai NS, Choudhari RS and Bapat VA (2007). RAPD markers for assessing culture induced variation in somatic embryogenesis derived plants of sugarcane. Sugar Tech. 9: 284-289.

Taylor PWJ, Geijskes JR, Ko HL, Fraser TA, et al. (1995). Sensitivity of random amplified polymorphic DNA analysis to detect genetic variation in sugarcane during tissue culture. Theor. Appl. Genet. 90: 1169-1173.

Wang LX, Cheng XZ, Wang SH, Liu CY, et al. (2009). Transferability of SSR markers from adzuki bean into mungbean. Acta Agro. Sin. 35: 816-820.

Wen MC and Kinsella JE (1991). Somatic embryogenesis and plantlet regeneration of Theobroma cacao. Food Biotech. 5: 119-138. 


\section{APPENDIX}

Appendix A. Polymerase chain reaction (PCR) conditions and concentrations of the reagents.

\section{RAPD analysis}

\section{Reaction mixture}

$\begin{array}{lcc}\mathrm{d} 3\left(\mathrm{H}_{2} \mathrm{O}\right) & & 8.3 \mu \mathrm{L} \\ \mathrm{PCR} \text { buffer }(10 \mathrm{X}) & (\mathrm{MBI}, \text { Fermentas) } & 2.5 \mu \mathrm{L} \\ \quad\left[\left(750 \mathrm{mM} \text { Tris-HCL, } \mathrm{pH} 8.8,200 \mathrm{mM}\left(\mathrm{NH}_{4}\right)_{2} \mathrm{SO}_{4}\right]\right. & & \\ \mathrm{dNTPs}(0.2 \mathrm{mM}) & \text { (MBI, Fermentas) } & 4.0 \mu \mathrm{L} \\ \mathrm{MgCl}_{2}(50 \mathrm{mM}) & \text { (MBI, Fermentas) } & 3.0 \mu \mathrm{L} \\ \mathrm{Gelatin}(0.025 \%) & \text { (Sigma Co. }) & 2.5 \mu \mathrm{L} \\ \text { Taq DNA polymerase }(5 \mathrm{U} / \mu \mathrm{L}) & \text { (MBI, Fermentas) } & 0.2 \mu \mathrm{L} \\ \text { Primer }(15 \mathrm{ng} / \mu \mathrm{L}) & \text { (Operon Technologies Inc., USA) } & 2.0 \mu \mathrm{L} \\ \text { Template DNA }(15 \mathrm{ng} / \mu \mathrm{L}) & 2.5 \mu \mathrm{L} \\ \text { Total volume } & & 25.0 \mu \mathrm{L}\end{array}$

For conducting PCR, all reagents, except DNA, were combined in one tube to make a master mix, and then aliquots of $23 \mu \mathrm{L}$ in labeled PCR tubes were kept on ice.

The DNA samples were amplified in a thermal cycler (Eppendorf DNA Thermal Cycler 9600) using the following PCR conditions.

\section{PCR profile}

Amplification was performed in an Eppendorf DNA Thermal Cycler 9600 programmed for a first denaturation step of $5 \mathrm{~min}$ at $94^{\circ} \mathrm{C}$ (initial denaturation), followed by 40 cycles of $1 \mathrm{~min}$ at $94^{\circ} \mathrm{C}$ (denaturation), $1 \mathrm{~min}$ at $36^{\circ} \mathrm{C}$ (primer annealing) and $2 \mathrm{~min}$ at $72^{\circ} \mathrm{C}$ for extension. The reactions were kept at $72^{\circ} \mathrm{C}$ for $10 \mathrm{~min}$ for a final extension step.

\section{SSR analysis}

\section{Reaction mixture}

d3 $\left(\mathrm{H}_{2} \mathrm{O}\right)$

PCR buffer (10X)

[(67 mM Tris- $\left.\left.\mathrm{HCl}, \mathrm{pH} 8.8,16 \mathrm{mM}\left(\mathrm{NH}_{4}\right)_{2} \mathrm{SO}_{4}\right)\right]$

dNTPs $(0.2 \mathrm{mM})$

$\mathrm{MgCl}_{2}(50 \mathrm{mM})$

Taq DNA polymerase $(5 \mathrm{U} / \mu \mathrm{L})$

Primer (30 ng $/ \mu \mathrm{L})$

Template DNA (30 ng/ $\mu \mathrm{L})$

Total volume

$\begin{array}{cr} & 3.0 \mu \mathrm{L} \\ \text { (MBI, Fermentas) } & 2.0 \mu \mathrm{L} \\ & \\ \text { (MBI, Fermentas) } & 6.8 \mu \mathrm{L} \\ \text { (MBI, Fermentas) } & 2.0 \mu \mathrm{L} \\ \text { (MBI, Fermentas) } & 0.2 \mu \mathrm{L} \\ \text { (GeneLink) } & 1.5+1.5 \mu \mathrm{L} \\ & 3.0 \mu \mathrm{L} \\ & 20.0 \mu \mathrm{L}\end{array}$

CFUNPEC-RP www.funpecrp.com.br 


\section{PCR profile}

Amplification was performed in an Eppendorf DNA Thermal Cycler 9600 programmed for a first denaturation step of $5 \mathrm{~min}$ at $94^{\circ} \mathrm{C}$ (initial denaturation) followed by 35 cycles of $45 \mathrm{~s}$ at $94^{\circ} \mathrm{C}$ (denaturation), $50-57^{\circ} \mathrm{C}$ for $45 \mathrm{~s}$ (primer annealing) and $72^{\circ} \mathrm{C}$ for $60 \mathrm{~s}(\mathrm{am}-$ plification or extension). The reactions were kept at $72^{\circ} \mathrm{C}$ for $7 \mathrm{~min}$ for a final extension step. 